\title{
CHATÔ: O REI DO ALGODÃO ${ }^{1}$
}

\author{
Chatô: the king of cotton
}

\author{
Maria Claudia Bonadio*
}

\begin{abstract}
RESUMO
O objetivo desse artigo é analisar o papel do empresário Assis Chateaubriand na promoção da moda brasileira durante o início da década de 1950 e como suas ações buscavam associar matériaprima nacional com a alta-costura francesa, deixando de lado as propostas nacionalistas que costumavam caracterizar sua atuação. Nesse sentido, entre 1951-1952, ele foi responsável pela vinda ao Brasil de três importantes nomes da alta-costura, Marcel Rochas, Jacques Fath e Elsa Schiaparelli. A partir do levantamento de reportagens publicadas em veículos de imprensa dos Diários Associados, a biografia do empresário e textos de sua autoria, intento ainda discutir como seus interesses no campo da moda, possivelmente estariam ligados a propósitos pessoais em relação à produção de algodão de fibra longa (ou algodão do Seridó) que, naquele momento, se concentrava em terras paraibanas, aonde Assis Chateaubriand vinha atuando como Senador e, provavelmente mantinha também investimentos econômicos.
\end{abstract}

Palavras-chave: alta-costura; algodão do Seridó, Assis Chateaubriand.

\begin{abstract}
The aim of this paper is to analyze the role of the entrepreneur Assis Chateaubriand in the fashion promotion in Brazil during the

1 Artigo resultante de pesquisa financiada pelo CNPq e desenvolvida como pósdoutoramento no Museu Paulista sob a supervisão da Profa. Dra. Vânia Carneiro de Carvalho. A autora agradece os bibliotecários Ivani Di Grazia Costa, Maíra Carvalho Moraes e Romeu Loreto da Biblioteca e Centro de Documentação do MASP pela gentileza no atendimento e colaboração com

* Universidade Federal de Juiz de Fora, Doutora em História pela Unicamp,
\end{abstract} essa pesquisa. mariacbonadio@uol.com.br 
early 1950s and how, in what refers to fashion, its actions sought to associate the national raw material with French haute-couture in a contradiction with the nationalist ideas which he uses to propagate. Thus, between 1951-1952 he was responsible for bringing to Brazil three important couturiers of French fashion: Marcel Rochas, Jacques Fath, and Elsa Schiaparelli. From the articles published in the Diários Associados media vehicles, the biography of the entrepreneur and texts written by him and spread in these newspapers and magazines I further noted, as their interests in fashion promotion, were possibly linked to personal purposes in relation to cotton of Seridó production, which at that time was produced in Paraíba where Assis Chateaubriand was Senator and probably also maintained economic investments.

Keywords: haute-couture, Assis Chateaubriand; cotton of Seridó.

\section{O Cruzeiro e a moda}

Durante o período da Segunda Guerra, a invasão de Paris pelos nazistas e as consequentes ações dos alemães para coibir a produção e as exportações de roupas produzidas pela alta-costura faz com que a moda norte-americana, em especial aquela comercializada pelas lojas de departamentos ganhasse espaço nos veículos de imprensa brasileiros. Na seção de moda da revista $O$ Cruzeiro, por exemplo, o designer gráfico Alceu Penna irá reproduzir (ou recriar) ilustrações de modelos propagados em catálogos de lojas americanas como Bonwitt Teller, Macy's, Saks.

Ainda que a influência do american way-of-life se intensifique no cotidiano dos brasileiros após o final do conflito mundial, no que diz respeito à moda, os Estados Unidos rapidamente perderão espaço para a França e as páginas dedicadas à moda das revistas brasileiras e, em especial $O$ Cruzeiro, voltarão a divulgar as novidades da alta-costura, ainda que, vez ou outra, veiculem algum material sobre a moda norte-americana.

Usando novamente como exemplo a revista $O$ Cruzeiro, no final de 1946, Alceu Penna viajará a Paris, onde passará a frequentar os salões de alta-costura e enviará semanalmente ilustrações que retratam as principais novidades da moda parisiense. A presença do 
costureiro na capital da moda será largamente explorada pelo semanário. Na primeira de suas colaborações provenientes de Paris veiculada na edição de 08 de dezembro de 1946, além dos croquis de peças de alta-costura serão mostradas fotografias de costureiros franceses no momento em que elaboravam croquis e como "prova irrefutável" da proximidade do ilustrador com o grand-monde da costura, uma foto do próprio Alceu desenhando um modelo de Balenciaga na Maison do costureiro. ${ }^{2}$

Ao mostrá-lo desenhando num ateliê de alta-costura em Paris, na mesma coluna onde eram exibidas as fotos dos costureiros Madame Carven e Marcel Rochas, a revista ampliava o status do ilustrador e colocava-o numa posição de autoridade em termos de moda - afinal de contas ele agora era um "frequentador" dos salões de alta-costura.

É também nesse momento, que a referida revista passará a publicar fotografias de moda, as quais mostravam peças de coleções internacionais - a maior parte francesa - que eram comentadas por Alceu Penna, que naquele já não era então apenas um ilustrador de moda, mas também o principal mediador entre o público leitor de $O$ Cruzeiro e a moda internacional. No período, a revista era a mais lida do Brasil, e sua tiragem média na década de 1950 chegava a 500 mil exemplares. Considerando que uma publicação não é lida apenas por quem compra, mas por um grupo maior de pessoas, como familiares ou clientes do comprador (no caso de revistas disponibilizadas em consultórios, por exemplo) podemos dizer que a fruição de seu conteúdo era ainda maior. ${ }^{3}$

Sem desprezar a importância dos periódicos femininos então em circulação, os quais também traziam informações de moda, é possível afirmar que $O$ Cruzeiro era o principal veículo difusor desse tipo informação, ou pelo menos, aquele que apresentava as novidades em termos de modade forma mais atrativa, com fotografias,

2 Segundo Susan Sontag a fotografia é comumente entendida como "testemunho", "Algo de que ouvimos falar mas, de que duvidamos parece comprovado quando nos mostram uma foto", mesmo diante de distorções a fotografia era utilizada comumente como "prova incontestável de que uma determinada coisa aconteceu". SONTAG, Susan. Sobre fotografia. São Paulo: Companhia das Letras, 2004, p. 16.

3 MIRA, Maria Celeste. O leitor e a banca de revistas. São Paulo: Olho d'água, 1998. 
ilustrações coloridas e um correspondente internacional. ${ }^{4}$ Mesmo o lançamento da revista Manchete em 1952, que adotando o modelo da do periódico ilustrada americano Life passará a divulgar maciçamente fotografias coloridas, não abalará a centralidade de $O$ Cruzeiro na divulgação de moda, pelo menos até meados da década de 1960.

Entre 1946 e até 1964 - quando Alceu Penna deixa de assinar a coluna de moda do periódico (para se dedicar à criação de moda da publicidade da Rhodia Têxtil) ${ }^{5}$ - é possível dizer que, se a moda francesa era o principal modelo difundido no País, O Cruzeiro era o espaço privilegiado para difusão dessa. Ainda que as capas da publicação fossem frequentemente estampadas com imagens de atrizes hollywoodianas, na seção de moda era a alta-costura que imperava.

Além da seção de moda, Alceu também assinava em $O$ Cruzeiro a coluna Garotas (1938-1964) - cujas ilustrações propagavam muito do estilo de vida e moda juvenis. ${ }^{6}$ As duas seções ocupavam em média quatro páginas por edição, podendo chegar a oito em algumas ocasiões, sendo duas páginas para as Garotas e o restante para a coluna de moda. Ainda que o largo espaço ocupado por Alceu na revista se deva à sua competência e bom relacionamento com Accioly Neto, diretor de $O$ Cruzeiro por quarenta anos, ${ }^{7}$ sua longa permanência no periódico, bem como o espaço ocupado por suas colaborações em outros veículos dos Diários Associados, possivelmente só ocorreu porque seu trabalho agradava à Assis Chateaubriand, dono do referido conglomerado das Comunicações. ${ }^{8}$

Os jornais e revistas publicados pelos Diários Associados mas especialmente $O$ Cruzeiro e A Cigarra - por sua popularidade,

4 O Jornal das Moças (1914-1965), por exemplo, no início dos anos 1950 veiculava fotografias de moda compradas de agências internacionais, as quais eram acompanhadas de textos breves. Ainda que tais informações fossem abundantes (ocupando uma média de 30 páginas em cada edição), não havia na revista um colunista de moda que produzisse textos ou ilustrações e tais conteúdos eram veiculados sem assinatura. Nversos, 2014.

5 BONADIO, Maria Claudia. Moda e publicidade no Brasil nos anos 1960. São Paulo:

6 PENNA, Gabriela Ordones. Vamos, garotas! Alceu Penna: moda, corpo e emancipação feminina (1938-1957). São Paulo: Annablume, 2010.

7 JÚNIOR, Gonçalo. Alceu Penna e as Garotas do Brasil. São Paulo: Cluq, 2004.

8 Alceu Penna prestou serviços para os Diários Associados entre 1934-1964 atuando entre outros em $O$ Cruzeiro e A Cigarra. 
alcance, projeto jornalístico e gráfico foram fundamentais para a propagação da moda internacional no Brasil. Assim seria possível afirmar que os veículos de imprensa de propriedade de Assis Chateaubriand foram centrais na difusão da cultura de moda no Brasil - como evidenciam os diversos trabalhos de pesquisa sobre o tema que tiveram tais revistas como fonte e objeto de estudo. ${ }^{9}$ Entretanto, no início da década de 1950 o interesse do empresário em relação à moda, parece ultrapassar a questão editorial, pois entre 1951-1952 ele foi o responsável pela vida ao Brasil de três importantes costureiros: Elsa Schiaparelli, Marcel Rochas e Jacques Fath.

As vindas de Schiaparelli e Fath até são mencionadas em livros como Chatô: O Rei do Brasil ${ }^{10}$ e História da Moda no Brasil ${ }^{11}$ e no artigo Arte, moda e indústria no Brasil na década de $1950,{ }^{12}$ mas um fator importante escapou a esses textos: que motivos teriam levado Chateaubriand a se preocupar com a moda no início dos anos 1950 ? Neste artigo, pretendo esboçar respostas para essas questões.

Outros pontos, que mesmo comentados pelos textos acima citados merecem maior atenção são: como a vinda de Jacques Fath ao Brasil e a festa realizada em seu castelo em Coberville na França também em 1952 (da qual tratarei adiante) estariam conectados? Seria a referida festa uma simples extravagância de Chatô como insinua Fernando Morais na biografia do empresário, ou parte de um projeto maior orquestrado por Assis Chateaubriand para promover o algodão

9 Dentre os estudos que utilizam e destacam a importância da revista para a moda no Brasil cito: ALMEIDA, Jaqueline Moraes de. Madames e mocinhas em revista: Corpo, gênero e moda em A Cigarra (1940-1955). Dissertação (Mestrado em História) - Universidade Estadual de Campinas, 2015; PENNA, 2010.; LIMA; 2009; BECKER, Gisele e CANDIDO, Luciane Aparecida Cândido. "Alceu Penna e a construção do vestuário infantil nas páginas da revista O Cruzeiro (1950-1959)." In: Anais do XIV Congresso de Ciências da Comunicação na Região Sul, 2013; JOFFILY, Ruth. Jornalismo de moda, jornalismo feminino e a obra de Alceu Penna. Dissertação (Mestrado em Comunicação), Universidade Federal do Rio de Janeiro, Rio de Janeiro, 2002; LIMA, Laura Ferrazza de. Vestida de frivolidades: a moda feminina em suas visões estrangeira e nacional na revista O Cruzeiro de 1929 a 1948. Dissertação (Mestrado em História), Universidade Federal do Rio Grande do Sul, 2009. e PENNA, Gabriela Ordones. Vamos, garotas! Alceu Penna: moda, corpo e emancipação feminina (1938-1957). São Paulo: Annablume, 2010.

10 MORAIS, Fernando. Chatô, o rei do Brasil. São Paulo: Companhia das Letras, 1994.

11 PRADO, André Luis e BRAGA, João. História da Moda no Brasil. São Paulo: Disal, 2011.

12 SALLES, Joana Pedrasoli. Arte, moda e indústria no Brasil na década de 1950: Christian Dior, Salvador Dali, Jacques Fath e Elsa Schiaparelli, in Iara: revista de moda, cultura e arte. vol. 2, n. 1, pp. 85-100. 
produzido na região nordeste $?^{13}$ Por fim, mas não menos importante, até que ponto as iniciativas de Chatô para a moda estariam conectadas com o pensamento dominante acerca da moda no Brasil?

\section{Moda no Brasil e alta-costura}

Até meados do século XX, a constituição de uma identidade visual brasileira para a moda, era uma questão que para o público em geral, e mesmo para a indústria têxtil e de confecção nacional, não se colocava. Naquele período, a maior preocupação destas indústrias era produzir tecidos e roupas que, na medida do possível, seguissem de perto os lançamentos da moda feminina parisiense: ${ }^{14}$ cores, modelos e padronagens eram imitados e apenas um ou outro detalhe era modificado.

Para a produção de estamparias era comum contratar artistas plásticos que tivessem habilidade para copiar os desenhos usados nos têxteis internacionais. ${ }^{15}$ Já para as lojas de luxo femininas como a Casa Canadá no Rio de Janeiro e a Casa Vogue em São Paulo, o segredo do sucesso era comprar em Paris as novidades da altacostura, e comercializar no Brasil - no caso da loja carioca, não sem antes analisar e reproduzir o modelo em outros tecidos e com alteração em alguns detalhes para vender a alguma elegante brasileira com a etiqueta Canadá de Luxe. ${ }^{16}$

Faltam estudos que tratem da moda comercializada pelas lojas de departamento nacionais como o Mappin, a Casa Slopper e

13 MORAIS, Fernando. Chatô, o rei do Brasil. São Paulo: Companhia das Letras, 1994.

14 MARINHO, Maria Gabriela SMC. Ensino Superior de Moda: condicionantes sociais de sua institucionalização acadêmica em São Paulo. In: WAJNMAM, Solange e ALMEIDA, Adilson. Moda, comunicação e cultura. São Paulo: Arte \& Ciência, 2005. Pp 15-28

15 NEIRA, Luz Gaudisio. Estampas na tecelagem brasileira. Da origem à originalidade. Tese de doutorado em Arquitetura, Faculdade de Arquitetura da Universidade de São Paulo, 2012.

16 SEIXAS, Cristina. A questão da cópia e da interpretação no contexto da produção de moda da casa Canadá no Rio de Janeiro na década de 50. Dissertação (Mestrado em Design), Pontifícia Universidade Católica do Rio de Janeiro, Rio de Janeiro, 2001. 
outras que atendiam às camadas médias no período, e que investiguem o que tais lojas vendiam.. Contudo, levando em conta os estudos sobre a indústria têxtil e casas de luxo, é possível supor que, para essas, o caminho mais seguro consistia em vender modelos que também seguissem de perto a moda parisiense, a um custo mais acessível. Prática também adotada por modistas e costureiras. ${ }^{17}$ Por esse motivo, a maioria das seções de moda veiculadas nas revistas nacionais até os anos 1960 atinham-se na maior parte do tempo, a veicular imagens das novidades da moda internacional, especialmente parisiense.

Diante desse contexto, em 1951, Pietro Maria Bardi, então diretor do Museu de Arte de São Paulo (MASP) realizou em parceira com Paulo Franco, diretor da Casa Vogue, um desfile de moda no Museu, que foi divido em 3 partes: na primeira foram apresentadas roupas de séculos passados pertencentes a acervos de museus; na sequência peças da última coleção do costureiro Christian Dior então o mais importante nome da alta-costura parisiense - e por fim uma peça criada por Salvador Dali fazendo alusão à mulher do futuro, o Costume de 2045 (peça doada ao Museu por Paulo Franco). Todas as peças foram apresentadas por manequins de Christian Dior e o evento prestigiado pela alta sociedade paulistana que assistiu as apresentações em trajes black-tie. ${ }^{18}$

Um ano mais tarde, o MASP abrigaria um novo desfile, no qual foi apresentada a Coleção Moda Brasileira concebida e realizada nas oficinas do Museu. Ainda que a iniciativa tenha contado com o apoio de indústrias têxteis (Ribeiro Industrial S.A, Industil S.A, Luftalla S.A. e Santa Constância) e da loja de departamentos Mappin, onde as peças foram comercializadas, a ideia de vestir roupas inspiradas nas "coisas do Brasil", como a fauna, a flora, a cultura indígena, as paisagens e elementos da cultura afro-brasileira parece não ter agradado o público, pois a iniciativa não se repetiu. $O$ objetivo de Bardi com essa coleção era colaborar na criação de uma identidade visual para a moda brasileira, e propagá-la, sobretudo, através das

17 MALERONKA, Wanda. Fazer roupa virou moda: um figurino de ocupação da mulher, São Paulo 1920-1950. São Paulo: Senac, 2007.

18 BONADIO, Maria Claudia. A moda no MASP de Pietro Maria Bardi (1947-1987). Anais do Museu Paulista, v. 22, n. 2, p.35-70. 
indústrias têxteis - pois, a indústria de confecção era incipiente no País. Paulo Franco, que o havia apoiado no ano anterior compareceu ao evento - dessa vez realizado no final da tarde e com plateia trajando esporte-fino - mas, não apoiou a realização. ${ }^{19}$ Em entrevista para a revista Jeans e Sportwear no início dos anos 1980, Bardi confessou que só posteriormente entendeu a surpresa de Franco, quando em 1952 lhe disse que intencionava lançar a moda brasileira. ${ }^{20}$ No Brasil dos anos 1950, a alta-costura francesa ainda era soberana em termos de moda.

Naquele momento, Paris voltava a ser o principal centro difusor de moda e sofisticação para os brasileiros e grande parte do Ocidente. Já em 1949, Christian Dior por exemplo, tinha boutiques em vários países europeus e da América do Sul, Central, África, colônias francesas e Estados Unidos. Em termos de moda "Tudo o que tinha a ver com a alta-costura parisiense aparentemente fascinava as mulheres americanas" 21 e, ainda que a moda americana tivesse ganhado espaço e identidade associada à roupa esportiva, no período era a moda parisiense que representava o alto luxo e o chic.

O status dos costureiros também se transformou nessa época, quando se tornam celebridades e "estrelas" da moda que vestiam as mulheres da alta sociedade. Muitos eram provenientes de famílias abastadas e costumeiramente assunto de revistas de variedades, que se interessavam por seus trabalhos e suas vidas. Christian Dior (19051947), por exemplo na década de 1950 foi capa de revistas como a americana Time e a francesa Paris Match. ${ }^{22}$ Uma pesquisa realizada na França em 1949 pelo Instituto Gallup detectou que Christian Dior era uma das cinco personalidades mais conhecidas no País. ${ }^{23}$ Jacques

19 Idem, ibidem.

20 Pietro Maria Bardi. Jeans e Sportwear, ano 1, n. 2, 1982, p.24-25.

21 STEELE, Valerie. Paris fashion: a cultural history. Berg: Oxford/New York, 1998, p. 274.

22 Se de modo geral a geração anterior tinha perdido muito tempo para se afirmar na escala social, os nomes que agora despontavam já começam a carreira de forma privilegiada e integrados ao mundo da alta sociedade. Dior estudou Ciência Política e atuou por alguns anos como marchand de artes, Jacques Fath era de família tradicional e rica, já Hubert de Givenchy era filho de um marquês e seu pai sonhava que fosse médico, mas acabou por cursar Belas Artes. No período, o prestígio crescente dos que abraçaram a profissão de criador de moda "foi resultado do prestígio que ela [a profissão] havia adquirido antes da guerra". CRANE, Diana. A moda e seu papel social. São Paulo: Senac, 2006. P. 301.

23 LIPOVETSKY, Gilles. O Império do efêmero. São Paulo: Companhia das Letras, 1989. 
Fath (1912-1954) por sua vez, era popular não apenas por suas criações, mas também pelas grandes festas que realizava em seu castelo e sua participação frequente em eventos, era um costureirocelebridade. ${ }^{24} \mathrm{Se}$ a costura parisiense do Pós-Guerra era considerada sinônimo de luxo e opulência, costureiros como Dior, Fath e Hubert de Givenchy (1927 -) eram a "encarnação da alta-costura parisiense". ${ }^{25}$

É também nesse período que os costureiros mais renomados passam a adotar um novo modelo de negócios, a criação de boutiques com seus nomes em Paris e ao redor do mundo, nas quais vendiam produtos mais acessíveis e ainda assim com a qualidade associada à marca. As boutiques comercializavam produtos licenciados, como meias-calças, cosméticos e peças de prêt-à-porter de luxo. Para criar a sensação de distinção, as lojas eram cuidadosamente decoradas criando a mesma aura de luxo que as maisons de alta-costura - essas especializadas na criação de modelos sob medida.

No Brasil o negócio das boutiques de costureiros estrangeiros ainda precisa ser mais bem estudado, mas sabe-se que Christian Dior, por exemplo, tinha uma boutique em São Paulo e há indícios que a loja era administrada pelo dono da já citada Casa Vogue, e talvez a participação no citado desfile no MASP, bem como a vinda de 4 manequins da marca para desfilar no evento tenha sido aceita com vistas a promover a boutique. ${ }^{26}$ Quem também teve boutique no Brasil foi o costureiro francês Jacques Heim, ${ }^{27}$ essa instalada na torre do edifício da Mesbla no Rio de Janeiro. ${ }^{28}$

Outra nova estratégia de atuação associada à alta-costura que se popularizou entre as casas de costura após a Segunda Guerra é a criação de modelos patrocinados por indústrias têxteis. Tais empresas

24 LYNN, Eleri. Jacques Fath. In: In: WILCOX, Claire. The Golden Age of Couture. Paris and London, 1947-1957. Londres: Victoria \& Albert, 2008. Pp.86-87.

25 In: LECALLIER, Sylvie. Paris, décor de La haute couture. In: SAILLARD, Olivier e ZAZZO, Anne (Dir.). Paris haute couture. Paris: Skira Flamarion, 2013, p. 219.

26 PALMER, Alexandra. Dior: A New Look, a New Enterprise (1947-1957). London: V\&A Publishing, 2009.

27 RAINHO, Maria do Carmo Teixeira. Notas sobre a presença de um costureiro francês no Rio de Janeiro (1958-1967). In: 9². Colóquio de Moda, 2013, Fortaleza. Anais Colóquio de Moda, 2013. v. 9.

28 PRADO, André Luís e BRAGA, João. História da Moda no Brasil. São Paulo: Disal, 2011. 
com vistas a promover seus tecidos, presenteavam costureiros com grandes metragens de determinado material, a partir dos quais eram elaboradas peças com assinatura da marca. As roupas elaboradas a partir dessas parcerias eram, muitas vezes eram divulgados em anúncios revistas de moda, como Vogue e L'Officiel. ${ }^{29}$

É diante desse contexto que três importantes nomes da altacostura virão ao Brasil entre 1951 e 1952, todos a convite do empresário das comunicações Assis Chateaubriand. São eles, Marcel Rochas, (1902-1955) Elsa Schiaparelli (1890-1973) e Jacques Fath.

\section{Elsa Schiaparelli}

É possível que a visita de Elsa Schiaparelli ao Brasil, realizada no segundo semestre de 1952, tenha sido uma viagem turística proporcionada por Chatô, mas, levando em consideração seu propósito de promover o algodão nacional e, por consequência, gerar eventos que colaborassem na promoção da indústria têxtil brasileira, é possível aventar que ao trazer a costureira ao País estivesse buscando aproximação com vistas a um futuro acordo comercial.

Chateaubriand e Schiaparelli teriam se conhecido em Paris por intermédio de amigos brasileiros. Provavelmente foi o empresário quem lhe apresentou a Darcy Vargas, presente nos desfiles realizados pela costureira italiana em Paris alguns dias antes da festa no castelo de Jacques Fath (da qual tratarei adiante). A presença da primeiradama no desfile é relatada por Schiaparelli em sua autobiografia, na qual dedica um capítulo ao que denomina "aventura rapsódica" no Brasil. $^{30}$

29 MILLER, Lesley Ellis. Perfect Harmony: Textile Manufactures and Haute couture 1947-1957. In: WILCOX, Claire. The Golden Age of Couture. Paris and London, 1947-1957. Londres: Victoria \& Albert, 2008. Pp. 113-135.

30 SCHIAPARELLI, Elsa. Shocking Life: The autobiography of Elsa Schiaparelli. Londres: Victoria \& Albert Museum, 2007, p. 94. 
O roteiro preparado por Chateaubriand para Schiaparelli é repleto de visitas a lugares que se coadunavam com os estereótipos do Brasil propagados no exterior, e especialmente pelos filmes de Walt Disney realizados no âmbito da política da "Boa Vizinhança", como "Alô Amigos" e "Você já foi à Bahia". A costureira é levada pelo empresário, por exemplo, à favela carioca Morro do Pinto, onde ocorreu uma cerimônia na qual foram exibidas três obras de Amadeo Modigliani (1884-1920) recém-adquiridas pelo MASP, seguida de uma apresentação de samba.

Schiaparelli também esteve em São Paulo, mas foi a Bahia que lhe chamou a atenção. A italiana gostou das igrejas incrustadas de ouro, do mercado popular (provavelmente em referência ao Mercado Modelo) - que em seu entender eram reminiscências dos mercados marroquinos -, e dos ritos do que ela chama de "magia negra" espalhados pela cidade, como por exemplo, a tradição de amarrar nos braços as fitinhas do Bonfim. Em sua autobiografia conta que visitou uma "macumba" onde se deixou envolver pelo ritmo dos atabaques e participou de um rito espiritual para "fechar o corpo", visitou a praia e se encantou com o que denominou "balé dos pescadores" nas praias soteropolitanas. Esteve ainda em Recife e Feira de Santana, ${ }^{31}$ onde recebeu de Chatô a Ordem do Jagunço. ${ }^{32}$

$\mathrm{O}$ roteiro pode ser considerado uma síntese daquilo que o empresário das comunicações entendia como as peculiaridades do Brasil, elementos que também caracterizavam a fotorreportagem de $O$ Cruzeiro, tais como "os contrastes entre o Brasil arcaico e o Brasil moderno, os tipos humanos regionais, as religiões, a vida urbana, os problemas sociais, o Carnaval e o futebol". ${ }^{33}$

Talvez o tour preparado por Chateaubriand para Schiaparelli visasse, entre outros encantar a costureira com as "coisas do Brasil".

31 Idem, ibidem.

32 A Ordem do Jagunço era uma condecoração criada por Assis Chateaubriand para homenagear pessoas ilustres. No ato da homenagem o condecorado deveria vestir gibão e chapéu confeccionados em couro cru de bode. Entre outras personalidades agraciou Winston Churchill e Getúlio Vargas com a referida ordem. Chateaubriand entendia que os vaqueiros nordestinos eram um dos principais signos indenitários do País. LYRA, Maria de Lourdes Viana. Guimarães Rosa, uma reflexão sobre a questão da identidade nacional. Revista de Letras, vol. 1/2., no. 28.

33 BURGI, Sérgio e COSTA, Helouise. As origens da fotojornalismo no Brasil: Um olhar sobre O Cruzeiro 1940-1960. São Paulo: Instituto Moreira Salles, 2012. pp. 25. 
E assim, quem sabe, conseguir que o País se tornasse inspiração para alguma de suas coleções, ou que ela viesse mais adiante a criar uma coleção de padronagens têxteis para alguma indústria nacional com vistas a promover o algodão do Seridó.

Se durante a década de 1930 Schiaparelli havia sido um dos mais expressivos nomes da costura parisiense, tendo inclusive figurado na capa da Time em agosto de 1934 - a qual lhe dedicou uma reportagem especial - nos anos 1950 sua situação era bastante diversa. Suas coleções já não causavam tanto impacto e no período em visitou o Brasil, provavelmente ela já vivia uma situação financeira complicada, motivo pelo qual em 1954 fecharia suas lojas e se aposentaria. Portanto, se Chateaubriand buscava em Schiaparelli uma possível parceira para iniciativas semelhantes àquelas que seriam encabeçadas por Jacques Fath em 1952, a situação não era favorável e a passagem de Schiaparelli pelo Brasil resultou apenas em meia dúzia de reportagens para veículos dos Diários Associados sobre sua (quase "surrealista") passagem pelo País.

\section{Marcel Rochas}

Marcel Rochas esteve no Brasil em 1951. Passou por algumas cidades de diferentes regiões e apresentou uma conferência no MASP. Em sua palestra tratou da história da moda, promoveu seus perfumes e o livro que acabara de lançar 1925-1950: Vingt Cinq Ans de Élégance a Paris (que não foi traduzido para o português).

Não é possível determinar com precisão os motivos de sua visita ao Brasil, mas, é provável que a viagem tenha ocorrido em razão da junção de seu interesse pelo País somada à intenção de Chateaubriand em se aproximar de nomes da alta-costura. Segundo a reportagem "É a moda uma força criadora da natureza e o costureiro não desenha sobre uma mesa - Conferência pronunciada pelo sr. Marcel Rochas, famoso costureiro e perfumista francês, no Museu de Arte" veiculada em 24 de abril de 1951 no Diário de S. Paulo, antes do início de sua palestra no MASP, Marcel Rochas teria agradecido 
aos Diários Associados pela oportunidade de realizar seu sonho (almejado por 20 anos) de conhecer o Brasil. A frase poderia ser considerada apenas um artifício do jornalista responsável pela matéria para valorizar a empresa, porém há indícios de que o costureiro tinha de fato interesse pelo País. Em 1947 Alceu Penna apresentou na revista $O$ Cruzeiro de 01 de fevereiro (p. 67.) um vestido de noite do costureiro chamado Rio, cuja inspiração teria sido a cidade do Rio de Janeiro.

Em sua viagem ao Brasil esteve em Pernambuco, Amazonas, Rio de Janeiro e São Paulo, mas apenas a passagem pela capital paulistana ganhou espaço em $O$ Cruzeiro, uma vez que não foram encontradas matérias na revista sobre sua passagem pelas outras localidades. Isso permite pensar que talvez a palestra tenha sido a contrapartida da visita patrocinada.

Em todas as reportagens que tratam da vinda do costureiro ao País localizadas no Centro de Documentação do MASP, há a menção ao fato de sua viagem ter sido uma promoção dos Diários Associados, ${ }^{34}$ o que leva a seguinte pergunta: Qual o objetivo de Assis Chateaubriand em trazer o costureiro ao Brasil? Apenas vender revistas?

O mais provável é que o empresário estivesse interessado em se aproximar de algum nome de destaque da alta-costura, para então convidá-lo a atuar na promoção do algodão nacional, mais precisamente aquele de fibra longa, conhecido como algodão do Seridó ou do Mocó, o qual era produzido nos estados do Rio Grande do Norte e Paraíba. Essa espécie da fibra têxtil e seus benefícios para a economia nacional passam a ser, no início dos anos 1950, um dos temas preferidos de Chateaubriand em seus escritos. Entre 1950 e até 1953 ele produziu mais de uma dezena de textos sobre o tema. ${ }^{35}$

34 Segundo dados encontrados na Biblioteca e Centro de Documentação do MASP, a indicação que os Diários Associados promoveram a viagem aparece em pelo menos dois artigos. Um no jornal Diário de S. Paulo, em 24 de abril de 1951, e o outro, num recorte de jornal sem data, com o título "Elegância e Moda", mas provavelmente publicado no dia 23 de abril, pois avisa que a conferência do costureiro aconteceria naquele dia.

35 Esse levantamento foi realizado na série de livros denominada $O$ pensamento de Assis Chateaubriand e mais especificamente nos volumes que correspondem aos anos 1950 a 1953 , publicados pela Fundação Assis Chateaubriand. 
A aproximação com Marcel Rochas aparentemente não trouxe maiores resultados e talvez o desinteresse em formalizar uma parceria decorra de o costureiro, apesar de já ser um nome estabelecido _ sua Maison estava em funcionamento desde 1925 - não se destacar na moda parisiense naquele momento. Assim, sua passagem pelo Brasil não repercutiu em outros órgãos de imprensa, além dos já mencionados Diário de S. Paulo e de $O$ Cruzeiro.

Ainda assim, a reportagem "Marcel Rochas visita o Brasil" veiculada em 07 de abril de 1951 em O Cruzeiro frisava a importância do costureiro:

Uma senhora brasileira que visitava a França pela primeira vez, indagava a uma amiga:

- Já estive na loja de Dior e de Fath. Comprei meia dúzia de modelos. Mas confesso que ainda não estou satisfeita; os vestidos são maravilhosos, quase perfeitos. Falta, contudo, alguma coisa; que não sei bem explicar o que seja. Onde eu poderia encontrar um costureiro que me apresente algo realmente único, mo modelo que não pudesse ser desenhado por quem quer que fosse? Um costureiro que não sofresse a influência muito forte de Dior e Fath?

A amiga que vive há anos em Paris e já está "naturalizada" respondeu prontamente:

- Para o que você quer só me lembro de um nome: Marcel Rochas. É o mais aristocrático dos costureiros.

O diálogo, possivelmente inventado pelo jornalista Rogério Duport - que o redigiu - evidencia a necessidade de promover o costureiro, a partir do apontamento daquilo que seria o diferencial de Rochas em relação a Dior e Fath, esses sim, duas das grandes estrelas da costura na década de 1950 .

Marcel Rochas era um costureiro que, apesar de reconhecido e respeitável, estava longe de ser uma das grandes estrelas da costura 
após o final da Segunda Guerra ${ }^{36}$. Jacques Fath, ao contrário, atingiu na primeira metade dos anos o auge de sua popularidade e era considerado um grande nome na alta-costura no período, como destaca a revista Life de 17 de outubro de 1949: "Dior costuma ser reconhecido como o maioral no mundo da moda, por assim dizer, mas o prestígio de Fath teve um crescimento espetacular e agora parece provável que será o responsável pelo próximo look a confrontar e empobrecer os Estados Unidos".

\section{Jacques Fath}

Mesmo tendo começado a produzir alta-costura em 1937 e no período da Segunda Guerra ter sido considerado colaboracionista, pois não se negou a atender a clientela formada pelas esposas dos oficiais alemães que ocuparam Paris durante a Guerra, não foi tachado de nazista. ${ }^{37}$ Após a Segunda Guerra sua carreira deslanchou e finalmente alcançou reconhecimento internacional. ${ }^{38}$ Além disso, a partir da segunda metade da década de 1940 passou a investir fortemente na propagação de uma imagem de luxo e glamour. Nos anos que seguem o fim do conflito mundial e num período em que a Europa atravessava uma crise financeira Jacques Fath teria gasto 3 mil dólares anuais em champanhe nos lançamentos de suas coleções, as quais costumavam ser descritas como "uma mistura de première Hollywoodiana com uma noite de estreia de uma ópera". ${ }^{39}$

36 No período 1949-1959, no jornal Folha da Manhã, o costureiro é mencionado apenas 27 vezes nas matérias sobre moda e 2 vezes no jornal $O$ Estado de S. Paulo.

37 VEILLON, Dominique. Moda e Gerra: um retrato da França Ocupada. Rio de Janeiro: Zahar, 2004.

38 Entre 1948 e 1959 o costureiro é mencionado 187 vezes no jornal Folha da Manhã, ficando atrás apenas de Dior, mencionado 191 no periódico entre 1951 e 1959. Já no jornal $O$ Estado de S. Paulo, Jacques Fath é mencionado 71 vezes entre 1949-1959 e Dior, 115. Jacques Fath também é bastante citado na revista Jornal das Moças, 33 vezes entre 1950-1959, contra 36 de Dior. A referida contagem foi realizada através de busca com os nomes dos costureiros nas bases digitais dos referidos periódicos no site da Biblioteca Nacional.

39 LYNN, Eleri. Jacques Fath. In: WILCOX, Claire. The Golden Age of Couture. Paris and London, 1947-1957. Londres: Victoria \& Albert, 2008. P. 86. 
Se Christian Dior era o nome mais popular da alta-costura, Jacques Fath era o que mais circulava em eventos de prestígio, sendo presença constante no Festival de Cinema de Cannes, jantares e festas. Costumava organizar festas à fantasia concorridíssimas em seu castelo. ${ }^{40}$ Era considerado à época, o segundo nome mais importante da alta-costura. ${ }^{41}$ Aparentemente, não possuía boutique no País, e nenhum outro negócio firmado no Brasil, mas era popular por aqui, sendo um dos nomes mais lembrados nas seções de moda de Alceu Penna para A Cigarra e $O$ Cruzeiro.

Com vistas a promover o algodão brasileiro produzido pela Bangu Têxtil, Jacques Fath e sua comitiva chegaram ao País em setembro de 1952 e iniciaram uma turnê que passou pelo Rio, São Paulo e Salvador, durante a qual foram realizados desfiles para exibir as peças em algodão brasileiro fabricado pela Bangu criadas pelo costureiro.

Ainda que a imprensa tenha veiculado maciçamente que a visita era resultado de um convite da Fábrica Bangu, cartas e outros documentos encontrados no Centro de Documentação do MASP permitem afirmar que foi Assis Chateaubriand que promoveu a vinda de Fath e sua equipe. Exemplar é a carta datada de 05 de julho de 1952, assinada pelo costureiro e dirigida a Assis Chateaubriand reclamando o atraso no envio dos tecidos. ${ }^{42}$

Na mesma carta Fath indica o número de quartos necessários para hospedagem, o roteiro do grupo e pergunta quanto será pago às manequins e a chefe da cabine (termo então utilizado para denominar o grupo de manequins de determinada Maison) e informa os custos dos vestidos que ele irá criar para algumas personalidades, incluindo a filha do presidente Getúlio Vargas, Alzira e a primeira-dama Darcy Vargas (100,00 francos cada). Não está claro se tais vestidos seriam usados na festa que aconteceria no mês de agosto no Castelo do

40 LYNN, Eleri. Jacques Fath. In: WILCOX, Claire. The Golden Age of Couture. Paris and London, 1947-1957. Londres: Victoria \& Albert, 2008. Pp.86-87.

$41 \mathrm{O}$ primeiro, Christian Dior, apesar de ser o mais estrelado costureiro no período, não poderia assumir tal tarefa, primeiro porque possuía uma boutique em São Paulo e segundo, porque tinha contrato com a Boussac Têxtil, o que provavelmente o impedia de assinar coleções de tecidos para outras indústrias do ramo.

42 Gaveta 1, Pasta 14, documento 26. Centro de Documentação do Museu de Arte de São Paulo. 
costureiro, ou durante as apresentações das peças criadas para a Bangu no Brasil, mas todos os acertos parecem ter sido realizados diretamente com o empresário das comunicações.

Ainda que a Bangu Têxtil tenha fornecido a matéria-prima necessária para as criações de Fath e que os desfiles realizados no Brasil tenham colaborado para promover a marca no País foi Assis Chateaubriand quem intermediou o contato entre os diretores da empresa e o costureiro. Levando em conta o conhecido gosto de Jacques Fath por festas é plausível que o polêmico evento festivo realizado no Castelo de Cobreville em 03 de agosto de 1952 tenha sido parte do acordo firmado entre Chateaubriand, Jacques Fath e Joaquim Guilherme da Silveira, proprietário da Bangu Têxtil. ${ }^{43}$

A atuação de Chateaubriand para a organização do evento é completamente apagada no livro comemorativo do centenário da indústria têxtil, Bangu 100 anos. $^{44}$ Nessa obra a festa tem espaço destacado e é mencionada como parte da estratégia de marketing adotada pela empresa a partir de 1952, cujo objetivo era realizar um evento de repercussão internacional. No livro a passagem é ilustrada com sete fotografias e além do pioneirismo da ação da empresa, também é ressaltada a "brasilidade" da festa, a qual segundo o texto contou com convidados vestindo fantasias "exóticas" como a de cangaceiro de Chateaubriand ou as carregadoras de flores - costume envergado por diversas senhoras da sociedade carioca, dentre as quais Candinha Silveira, esposa do dono da Bangu - inspiradas em gravuras de Debret.

43 Tanto a festa Carnaval à Rio, como a vinda ao Brasil parecem ter sido relevantes para a carreira do costureiro, pois ainda que a menção a ambos seja rápida há diversas fotografias dos eventos no livro biográfico denominado Jacques Fath. GUILLAUME, Valerie. Jacques Fath. Paris: Adam Biro/Paris Musée, 2000.

44 Bangu 100 anos. A fábrica e o bairro. Rio de Janeiro: Sabiá produções artísticas, 1989. 


\section{Algodão do Seridó, um produto "alta-costura"}

O Carnaval a Rio, nome oficial da festa organizada por Chateaubriand e patrocinada pelo dono da Bangu Têxtil no castelo de Jacques Fath, nas redondezas de Paris contou com a participação de 3 mil pessoas que puderam assistir ali apresentações de ritmos brasileiros, executados pela Orquestra Tabajara; das cantoras Elizeth Cardoso e Ademilde Fonseca, que cantavam respectivamente samba canção e choro; do sanfoneiro Zé Gonzaga, do sambista Jamelão e Pato Branco (um sanfoneiro albino que se passava por Sivuca), além de vinte passistas baianas. Durante a festa os cantores e músicos tocaram ritmos como frevo, xaxado, samba, cateretê, e cururu. O evento contou também com uma cavalhada da qual participaram Arbusse Bastide, Danuza Leão, Elsa Schiaparelli e Assis Chateuabriand, todos vestindo roupas de vaqueiro, com exceção da costureira italiana que estava fantasiada de Periquito do Guaíba. O anfitrião recebeu a todos com uma fantasia de índio estilizada, trajando apenas tapa-sexo e cocar. Entre os convidados, personalidades internacionais, como Orson Welles, as atrizes Ginger Roger, Carole Lombard, Claudette Colbert, Paulette Goddard, o ator francês Jean Louis Barrault, o comediante americano Danny Kaye e também a primeira-dama Darcy Vargas e sua filha Alzira. ${ }^{45}$

A festa foi o grande escândalo social daquele ano e acabou apelidada pela imprensa que se opunha à Getúlio Vargas e a Assis Chateaubriand de "Bacanal em Coberville". 46 Não faltaram insinuações de que Vargas teria utilizado verbas públicas para pagar os voos da Panair que transportaram músicos e convidados ${ }^{47}$.

Como informa a reportagem "Dólar em câmbio negro na farra do Castelo" do Correio da Manhã, veiculada poucos dias após a festa, em 07 de agosto, o pretexto para a realização do evento seria a

45 Nervosismo e expectativa pela festa de Jacques Fath. In: Diário Carioca, 06 de agosto de 1952, p. 07.

46 MORAIS, Fernando. Chatô, o rei do Brasil. São Paulo: Companhia das Letras, 1994 , p. 529.

47 MORAIS, Fernando. Chatô, o rei do Brasil. São Paulo: Companhia das Letras, 1994 , p. 529. 
promoção do algodão nacional na Europa, de tal modo que o evento também ficou conhecida como Festa do algodão do Seridó. Durante a festa, o algodão brasileiro não foi apresentado através de desfile de moda, mas nas roupas das convidadas brasileiras, inclusive a primeira-dama e a filha de Vargas, que usavam vestidos confeccionados com algodão Bangu.

O evento repercutiu inclusive fora do País, sendo comentado em uma reportagem ilustrada da revista australiana "The Australian women's weekly" de 24 de setembro de $1952 .{ }^{48}$ Fotos sobre o evento também são encontradas no banco de imagens da agência de fotografias Magnum Photos. ${ }^{49}$

É possível que a festa brasileira em Coberville tenha sido uma exigência de Fath, afinal dessa maneira ele poderia entrar em contato com a cultura brasileira - mesmo que filtrada pelos olhos de Chateaubriand - e assim buscar inspirações para as peças que criaria com o algodão Bangu. $\mathrm{O}$ interesse do costureiro acerca da cultura brasileira - muito provavelmente influenciado por aquilo que via nos filmes hollywoodianos, posto que, em alguns momentos, faz uma miscelânea entre Brasil e América Latina ${ }^{50}$ - é evidenciado já na carta enviada à Chateaubriand, a quem solicita o envio de discos com música brasileira dos séculos XVIII, XIX e XX, em especial aqueles de samba, rumba e mambo! Pede ainda, documentos sobre folclore, acessórios como chapéus Panamá, chapéus brasileiros, maracas e redes de algodão branco. Pergunta ainda se o maxixe é uma dança autenticamente brasileira.

$\mathrm{Na}$ carta citada, não está claro se os pedidos de Fath são especificamente para a festa - como parece ser o aquele relativo às danças típicas -, se para inspirar suas criações, ou para ambos. Também no documento é possível observar que algumas das apresentações musicais e de dança que aconteceram durante a festa

48 Fabulous Paris Party. The Australian women's weekly. 24 de setembro de 1952, p. 3. Diponível em: <http://trove.nla.gov.au/aww/read/185959?q=jacques+fath\&s=20\&resultId=num22\#page/2/mode/1up> acesso em 14 de abril de 2017.

49 Disponível em: https://www.magnumphotos.com/Catalogue/DavidSeymour/1952/FRANCE-Paris-Holiday-1952-NN141257.html, acesso em 12 de outubro de 2016.

50 Sobre o tema ver: Freire-Medeiros, Bianca. O Rio de Janeiro que Hollywood inventou. Zahar, 2005 e Garcia, Tânia da Costa. O" it verde e amarelo" de Carmen Miranda (19301946). Annablume, 2004. 
resultaram de uma solicitação do costureiro, que solicitou exibições de frevo e "cha-cha", além de música orquestrada.

A repercussão negativa da festa de Coberville não parece ter prejudicado a recepção da coleção, pois sua passagem pelo Brasil recebeu grande cobertura da imprensa e a única menção de repúdio à sua presença no País foi publicada inicialmente no jornal Tribuna da imprensa, de Carlos Lacerda, então um dos principais opositores de Getúlio Vargas ${ }^{51}$ e reproduzida no jornal O Estado de S. Paulo, pertence à família Mesquita, tradicional inimiga de Chatô. ${ }^{52}$ Mas, se tratava de uma pequena nota veiculada num espaço exíguo em 25 de setembro de 1952, a qual informava que na reunião da Comissão da Moral e Bons Costumes da Confederação da Família Cristã ocorrida no dia 19 daquele mês foi "decidido enviar carta de protesto ao patrocínio de damas da nossa sociedade à visita do costureiro francês Jacques Fath, atualmente no Rio e em cujo castelo se realizou uma festa indecorosa". ${ }^{53}$

A cobertura, entretanto, foi majoritariamente muito simpática à passagem do costureiro e sua trupe pelo País. No Jornal do Brasil de 18 de setembro de 1952, por exemplo, o texto de Maria Eugênia Celso na seção "Notas Sociais" frisa a expectativa em torno do desfile a acontecer no Copacabana Palace, informa que o mesmo será beneficente e que o desfile traz novamente à tona o baile ocorrido em Coberville, o qual em sua opinião teria sido demasiadamente caluniado. ${ }^{54}$

O jornal A Manhã de 09 de setembro de 1952 também era simpático ao evento e informava que o desfile a acontecer no Copacabana Palace iria misturar peças da coleção atual do costureiro e outros criados com o algodão Bangu e contava ainda como eram os modelos de roupas que a esposa do costureiro, Geneviève Fath -

51 Dicionário Histórico Biográfico Brasileiro pós 1930. 2ª Edição. Rio de Janeiro: Editora FGV, 2001.

52 MORAIS, Fernando. Chatô, o rei do Brasil. São Paulo: Companhia das Letras, 1994.

53 Lacerda, Carlos. A dança sobre o vulcão. O Estado de S. Paulo, 25 de setembro de 1952, p. 14. Caderno, p. 8 .

54 Celso, Maria Eugênia. Notas Sociais. Jornal do Brasil. 18 de setembro de 1952, $1^{\circ}$. 
conhecida por sua beleza a elegância - iria usar em sua estadia no País. ${ }^{55}$

Jacques Fath veio ao Brasil em setembro de 1952, mas a cobertura de sua passagem só foi noticiada pela revista $O$ Cruzeiro nos meses seguintes (outubro e novembro), quando seria tema de diversas reportagens veiculada sem quatro edições. Na matéria da série veiculada em 08 de novembro, o texto de Alceu Penna enfatizava que "pela primeira vez na história da moda um costureiro apresentou uma coleção com tecidos que não eram franceses" e que tal mérito coube à Fábrica Bangu, que trouxe Fath ao Brasil. A reportagem traz fotos coloridas dos vestidos apresentados em São Paulo, Rio de Janeiro e Salvador e mais uma vez em tom ufanista do que provavelmente se trata de uma reportagem encomendada por Assis Chateaubriand, Alceu Penna diz que "pela primeira vez as mulheres brasileira vão ter a glória de usar o 'dernier-cri' de Paris em 'primeira mão', sem conhecer as desvantagens do atraso com que chegam aqui, que por via disso andam sempre mais ou menos atrasados em relação à estação ou às variações de clima setentrional. $" 56$

Em seu texto, Penna explica que os amplos decotes dos vestidos (todos em estilo cocktail) seriam uma adaptação dos modelos do costureiro ao clima local, uma vez que eram confeccionados em algodão Bangu - ainda que alguns levassem detalhes em veludo ou seda, estes "destinados a realçar a beleza".

$\mathrm{Na}$ semana seguinte, outra reportagem, essa escrita por Luís Marinho tratava do tema, com o título "Jacques Fath foi à Bahia". Na matéria, o jornalista tentava convencer o consumidor que a iniciativa em criar modelos com os tecidos nacionais haveria ocorrido após a festa do castelo de Coberville quando o costureiro teria ficado impressionado com a qualidade dos tecidos nacionais. $\mathrm{O}$ texto provavelmente outra encomenda de Chateaubriand - tentava justificar porque Fath teria ido à Bahia: "A Bahia esteve presente nas belas

55 Jacques Fath no Rio de Janeiro (seção Notas e Notícias). A Manhã. 09 de setembro de 1952 , p. 3.

56 PENNA, Alceu. Modelos de Fath com tecidos Bangu. O Cruzeiro. 08 de novembro de 1952. pp. 66-67.

57 Idem, ibidem. 
baianas que levantaram a festa de Coberville, a Bahia esteve presente nos sambas, nos poemas das canções populares e criou-se uma atmosfera de interesse pela Bahia. ${ }^{58}$

A apresentação do desfile em Salvador até pode ter resultado de um pedido de Fath, porém, o mais provável é que tenha sido uma iniciativa de Assis Chateaubriand, pois um roteiro parecido foi realizado quando da visita de Elsa Schiaparelli, que esteve em Recife, São Paulo, Rio de Janeiro e Salvador - onde passou a maior parte do tempo. Das quatro cidades, apenas Recife ficou fora do roteiro do costureiro. ${ }^{59}$

Quaisquer que tenham sido os motivos da opção por levar os personagens da alta-costura à Salvador, o que sabemos de concreto é que na visita de ambos, Chateaubriand priorizou mostrar-lhes elementos da cultura afro-brasileira. Assim, Schiaparelli visitou um terreiro - e ficou encantada com os rituais do candomblé -, Fath assistiu, como prólogo do seu desfile (que só começou após a 1 hora da manhã!), à exibição de vestimentas do candomblé exibidas por senhoras da alta-sociedade soteropolitana, uma apresentação de capoeira e um discurso de Chateaubriand e Régis Pacheco (18951987), então governador do Estado.

Nesse desfile, como nos outros dois já realizados no País, foram mostradas as criações do costureiro com tecido nacional, e os modelos apresentados receberam denominações que mesclavam referência ao luxo e sofisticação associados à França em modelos como Paris e Versalhes, à cultura e cidades brasileiras expressos em nomes como Frevo, Maracatu, Rio e Petrópolis (o que talvez seja resultado da mistura no desfile de peças criadas para a coleção parisiense e para a aquela realizada com tecidos brasileiros). A observação dos vestidos, entretanto leva a crer que os nomes eram apenas uma forma de associar as peças ao Brasil, pois, não há nestes, qualquer elemento que evidencie a relação visual entre as peças e o

\footnotetext{
59 Não é possível precisar a data exata da vinda de Schiaparelli ao Brasil, mas sua visita é tema de uma matéria na revista $O$ Cruzeiro em 29 de novembro de 1952, o que leva crer que ocorreu em data aproximada à visita de Jacques Fath. MARIO, Luiz. Ordem do vaqueiro para Schiaparelli. O Cruzeiro. 29 de novembro de 1952. n. 7, pp. 110-112.
} $88,89,90$

58 MARIO, Luiz. Jacques Fath foi à Bahia. O Cruzeiro. 15 de novembro de 1952. pp. 
País. Os tecidos seguem a linha da moda então vigente, os modelos idem.

A principal novidade apresentada pela coleção é o uso do algodão, uma vez que, de modo geral, os vestidos estampados propostos pela alta-costura costumavam usar seda ou outros tecidos finos. Ao propor os vestidos em algodão, mesmo que a partir de uma estratégia publicitária orquestrada por Chateaubriand, Jacques Fath ia ao encontro daquilo que, mesmo de forma incipiente, era então entendida como a principal característica do vestir brasileiro, o uso do algodão.

Tal temática já aparecia na seção de Alceu nos anos 1940, como em 25 de abril de 1942, quando apresenta 3 looks confeccionados com o tecido e diz: "Para nós brasileiros, as modas de algodão, de que somos produtores desde a planta até o tecido, possuem particular interesse". Em diversas ocasiões as roupas feitas com a referida matéria-prima são anunciadas com destaque na seção de moda assinada por Alceu recebendo o título "Algodão", coisa que não ocorre quando as peças anunciadas são de outros materiais.

O algodão naquele momento era visto como um "tecido nacional", pois era produzido no País e até meados dos anos 1960 o tecido mais vendido no Brasil, portanto mesclá-lo à alta-costura era uma forma de elevar o status do produto nacional que, por essas épocas, atingia preços elevados e também sofria de defasagem em relação aos produtos importados. ${ }^{60}$

Não é possível mensurar a recepção das padronagens utilizadas por Fath quando estas chegaram às lojas, mas propagandas da Companhia de Tecidos Antinori e Casas Pernambucanas, que comercializaram os produtos, foram veiculados na capa no jornal $O$ Estado de S. Paulo no dia 28 de setembro - informando que a partir

60 Segundo relatório da Cepal divulgado em 1962, a indústria têxtil brasileira chega à década de 1960 com uma série de problemas já presentes no período da vinda de Jacques Fath. O equipamento têxtil era obsoleto e como consequência, o produto final de baixa qualidade. $80 \%$ dos fusos e $70 \%$ dos teares utilizados para a tecelagem de algodão estavam obsoletos, ou seja, tinham mais de 30 anos de uso (logo, mais de 20 em 1952) ou aparentavam características técnicas atrasadas e/ou precárias. O relatório revela que o obsoletismo era alto também nas outras fases do processo produtivo, como preparação da fiação para tecelagem e em menor amplitude no acabamento. CEPAL/ONU. A indústria têxtil do Brasil: Pesquisa sobre as condições de operação nos ramos de fiação e tecelagem, 1962. vol. 1. (mimeo). Sobre o tema ver também: STEIN, Stanley. Origens e Evolução da Indústria Têxtil no Brasil - 1850-1950. Rio de Janeiro: Campus, 1979. 
do dia seguinte os tecidos desenhados pelo costureiro poderiam ser encontrados para a venda naqueles estabelecimentos. A veiculação desses anúncios na primeira página do jornal leva a crer que a publicidade entendia que a expectativa pelo produto era grande, ou pelo menos pretendia forjar tal expectativa. ${ }^{61}$

Um dado curioso possível de verificar nesses anúncios é que apesar de grande parte das reportagens sobre a promoção indicarem que o algodão utilizado pelo costureiro em suas criações havia sido fabricado pela Bangu, um anúncio veiculado em 30 de setembro na página sete do jornal $O$ Estado de $S$. Paulo, informa que os tecidos com padronagens desenhados por Jacques Fath foram produzidos pelas indústrias têxteis Bangu, Corcovado e América Fabril. ${ }^{62} \mathrm{O}$ que talvez tenha ocorrido, é que de fato tais companhias também forneceram algodão para as criações, mas não financiaram os desfiles, muito menos a festa no Castelo, assim, apesar de serem fabricantes do tecido, não eram mencionadas no material divulgado para a imprensa. $^{63}$

\section{Moda e política}

Não é possível precisar quais motivos levaram Assis Chateaubriand a se interessar na promoção da moda nacional, e especialmente daquela produzida a partir do algodão fabricado na região do Seridó, mas é bem possível que tais iniciativas sejam motivadas por propósitos políticos, ou pessoais.

Em 1952, a partir de uma manobra política, Chatô se elegeu Senador pela Paraíba e ainda que artigos de sua autoria sobre a

61 Tecidos Bangu (anúncio). O Estado de S. Paulo. 28 de setembro de 1952, p. 1.

62 Algodão Seridó (anúncio). O Estado de S. Paulo. 30 de setembro de 1952, p. 7. Outro dado que corrobora a impressão foi encontrado em uma reportagem sobre a festa no Castelo de Coberville, publicada no Diário da Noite, de 16 de agosto de 1952, p. 8, ao mostrar a fotografia de Aimée Heren, informa na legenda que ela usava vestido de algodão da Corcovado.

63 Também no já citado livro Bangu 100 anos, todas as promoções são mencionadas como iniciativas da Bangu. 
importância do algodão do Mocó sejam encontrados desde anos anteriores, é possível que ao assumir o cargo, tenha se empenhado ainda mais em tal objetivo, posto que a valorização dessa matériaprima colaboraria para o crescimento da região.

O Nordeste havia sido um importante produtor de algodão no Brasil do século XIX, mas à medida que "verifica-se a expansão da lavoura algodoeira em São Paulo e, posteriormente no Paraná, inclusive por razões de ordem técnica" a região foi perdendo a relevância como fornecedora de algodão para a indústria têxtil, ${ }^{64}$ entretanto, apesar de perder importância relativa para o Centro-Sul, a produção do algodão no Nordeste continuava sendo uma das suas principais culturas. ${ }^{65}$

O interesse de Chateaubriand na promoção do algodão do Seridó fica evidente nos textos que publica sobre o tema entre 19511953 em diversos órgãos de imprensa dos Diários Associados. ${ }^{66}$ Em artigo de 03 de outubro, por exemplo, ao falar dessas ações destaca que, após passar por São Paulo e Rio de Janeiro, o desfile de Jacques Fath seguiu para a Bahia, e que a escolha dessa capital para exibir o desfile não foi nada fácil, pois outras três "grandes metrópoles disputavam as primícias do show Seridó-Bangu". Afirma ainda que, escolheu a Bahia em razão da atuação forte dos Diários Associados no Estado e que "O que a manufatura Bangu, no Rio e o atelier de Fath, em Paris conseguiram com o algodão de fibra longa brasileira dá para quebrar os dentes de todas as campanhas da difamação e da inveja. O que acabaste de contemplar, no corpo das louras faceiras da

64 CRUZ, Mercia Santos; MOREIRA, Ivan Targino e MAIA, Sinézio Fernandes. As exportações brasileiras de algodão na segunda metade do Século XX. In: CONGRESSO BRASILEIRO DE ECONOMIA E SOCIOLOGIA RURAL, 46., Cuiabá, 2004. Anais. Brasília: SOBER, 2004, http://www.sober.org.br/palestra/12/03O172.pdf

65 KEHRLE, Luiz. A cadeia produtiva de têxteis e confecções em Campina Grande Paraíba: oportunidade de investimentos no início dos anos 2000. In: TIRONI, Luiz Fernando (org.) A industrialização descentralizada: sistemas industriais locais. Brasília: IPEA, 2001. Pp.418- 450.

66 Reunidos numa série de livros denominada "O pensamento de Assis Chateaubriand", editada pela Fundação Assis Chateaubriand, em volumes que apresentam toda a produção textual do empresário, organizados por ano. 
terra doce, de França, mostra as largas possibilidades que se desatam ao futuro da riqueza do Seridó". ${ }^{67}$

No tom enfático que lhe era peculiar, Chatô responde de uma só vez às críticas à dispendiosa festa em Coberville, como aos rumores de que ele mesmo teria pago ao costureiro para que este criasse as referidas estampas de modelos (o que efetivamente fez). O texto prossegue afirmando que o algodão de fibra longa, além de fornecer o excelente resultado exibido nas passarelas, era matériaprima fértil e, ao contrário da ideia difundida que seu cultivo era restrito à região do Seridó no Nordeste (e mais especificamente nos Estados da Paraíba e Rio Grande do Norte), tal espécie poderia ser encontrada também em algumas regiões de Minas Gerais. O texto era portanto, uma evidente autodefesa, uma vez que seus opositores estavam apontando aquilo que, a leitura da série de textos de Chatô sobre o tema evidencia, ou seja, que tal empreitada era proveniente dos interesses pessoais de Assis Chateaubriand.

Em artigo publicado em 13 de dezembro de 1951 denominado "A missão dos paulistas no Nordeste algodoeiro" explica que "Desde anos somos nós outros, nas 'Fazendas Associadas' pequenos cotonicultores, integrados no esforço de suprimento do parque industrial bandeirante, consagrado à fiação e tecelagem da nossa fé." $" 68$

Em suas argumentações, Chateaubriand explicava que se a indústria era o principal caminho para o crescimento da nação - se coadunando com pensamento governamental da época ${ }^{69}$ - para que esta tivesse um bom desempenho, era preciso investir na agricultura, logo na matéria-prima para a indústria e em especial para aquela produtora de têxteis, como quando diz, por exemplo,

67 CHATEAUBRIAND, Assis. "Pelo Seridó e pelos vaqueiros dos nossos sertões" (publicado em 03 de outubro de 1952). In: O pensamento de Assis Chateaubriand. Brasília: Fundação Assis Chateaubriand, 1992-2002. Volume 29, P. 628.

68 CHATEAUBRIAND, Assis. "A missão dos paulistas no Nordeste algodoeiro" (13 de dezembro de 1951). In: O pensamento de Assis Chateaubriand. Brasília: Fundação Assis Chateaubriand, 1992-2002. Volume 28, p. 820.

69 FONSECA, Pedro Cezar Dutra. Gênese e precursores do desenvolvimentismo no Brasil. Pesquisa \& Debate, São Paulo, vol. 15, n. 2, pp. 225-256. 
O gênio da civilização, o qual brilhou no Nordeste, durante os albores da descoberta, com o açúcar transplantou-se para a Bahia e o Sul, primeiro no ouro, depois no café, e agora no edifício industrial. Mas as peças desse edifício na parte têxtil têm no Mocó uma trave mestra. Tem o solo do Nordeste uma predestinação para o sucesso do algodão de fibra longa. Mas pobre de recursos a região nordestina para dar à cultura algodoeira a plenitude de prosperidade, que ela reclama, deverão os paulistas constituírem nos artesões do largo processo de recuperação e de expansão, que a nobre fibra espera do Brasil dos nossos dias. ${ }^{70}$

Apesar da maior parte dos textos de Chateaubriand sobre o tema ter sido divulgada entre 1950-1952, a promoção do algodão do Seridó não foi um projeto tão fugaz, e em 19 de outubro de 1955, a promoção da matéria-prima seria retomada, desta vez com a realização da "Noite Brasileira em Assunção" no Paraguai. ${ }^{71} \mathrm{O}$ evento consistiu em um desfile de moda cujas roupas foram produzidas com algodão fabricado pela América Fabril e Corcovado. Na ocasião uma matéria publicada no Diário da Noite (pertencente aos Diários Associados) frisava: "Há quem afirme ser o Nordeste um pé morto da economia nacional. Mas esses por certo, desconhecem que a propaganda brasileira no exterior muito deve a um produto oriundo daquelas bandas: o algodão Mocó de fibra longa". ${ }^{72}$ Apesar de não ser assinado, a semelhança e o tom do texto - próximos àqueles compilados na série $O$ pensamento de Assis Chateaubriand - levam a crer que foi redigido pelo empresário.

70 Idem, Ibdem.

71 Noite brasileira em Assunção. Diário da Noite. 19 de outubro de 1955, p. 1.

72 Idem, Ibdem. 


\section{Moda estrangeira, matéria-prima nacional}

A defesa do desenvolvimento da indústria nacional "fundamentada na produção de bens a partir de matérias-primas da indústria brasileira" ${ }^{73}$ era um dos principais pontos do ideário político de Chateaubriand, portanto a defesa do algodão do Seridó, ainda que, por ventura, o beneficiasse pessoalmente estava em acordo com ideias que permearam seu pensamento desde a década de 1920 .

Como parte dessa proposta, no início da década de 1950, ao se envolver com ações ligadas à moda visava emprestar o prestígio da alta-costura ao produto nacional, sem intenção de alterar as estruturas do campo então vigentes, ou criar uma identidade visual para a moda ou tecido brasileiros. O objetivo era demonstrar que a partir da matéria-prima nacional era possível obter resultados tão bons quanto, aqueles conseguidos com tecidos importados.

Se o "Carnaval em Coberville" tinha por objetivo

apresentar à alta sociedade do Velho Mundo o Brasil verdadeiro, o Brasil que somos nós: um Brasil de mestiços autênticos, mulatos inzoneiros, índios e negros a promover a vasta experiência de cruzamentos que empreendemos no trópico, em vez do falsificado Brasil branco, de catálogos de grã-finos que, parvenus e snobs, tentam impingir filauciosamente ao mundo. ${ }^{74}$

A parceria das referidas tecelagens com Jacques Fath, ainda que visasse valorizar o algodão nacional, se distanciava do discurso nacionalista empregado em defesa da festa em Coberville, pois em nada aproximava moda e cultura brasileira.

73 MATOS, Júlia Silveira. O ideário nacionalista nos escritos de Sérgio Buarque de Holanda e Assis Chateaubriand: 1929-1932. Tese de doutorado em História, PUC-RS, 2008.

74 MORAIS, Fernando. Chatô, o rei do Brasil. São Paulo: Companhia das Letras, 1994, p. 527. 
A cultura brasileira poderia dar uma boa festa, mas ao tratar de moda, Chateaubriand parecia mais conservador, ou pelo menos, em se tratando de negócios, preferia apostar naquilo que já estava consolidado, no caso a alta-costura francesa. Ainda que os órgãos de imprensa dos Diários Associados tenham dado bastante espaço para o já mencionado desfile "Moda brasileira" em seus veículos de comunicação (além de reportagens na revista $O$ Cruzeiro, nos jornais do grupo, o desfile também foi transmitido pela TV Tupi), em seus textos (veiculado nos mesmos órgãos), o empresário, ao bradar acerca das qualidades do algodão do Mocó, em nenhum momento se refere ao desfile ocorrido no MASP - recurso que poderia ter utilizado como forma de somar mais um argumento em defesa de suas ações na promoção do algodão, pois era próximo a P.M. Bardi e tinha conhecimento das referidas ações. ${ }^{75}$

No entender de Chatô, a matéria-prima deveria ser nacional, mas o design, francês. Tal proposição acabava por evidenciar uma contradição em seu próprio pensamento, que era, em grande parte, pautado pela questão da "autenticidade" do nacional- muitas vezes evocado com vistas a combater o "estrangeiro"76. Assim, ao mesmo tempo em que bradava o nacional em seus escritos, acabava, também, por reproduzir um pensamento colonialista, para o qual os países "colonizados", produtores de matéria-prima se submetiam à dominação cultural e econômica de outro País. ${ }^{77}$ Podíamos ter o samba, o baião, as baianas, os cangaceiros e tudo o mais que foi exibido na festa de Coberville, mas não a moda.

RECEBIDO EM: 01/03/2017

APROVADO EM: 10/07/2017

75 Cabe lembrar que Pietro Maria Bardi, nascido na Itália, se mudou para o Brasil em 1947 a partir do convite de Assis Chateaubriand para dirigir o museu idealizado pelo empresário, o MASP. Sobre a relação de Bardi e Chateaubriand e Bardi ver: BARDI, Pietro Maria. Sodalício com Assis Chateaubriand. São Paulo: Museu de Arte de São Paulo Assis Chateaubriand, 1982.

76 Em sua concepção, a "autenticidade nacional" era composta pelo mito das três raças e pela música popular, se coadunando com o pensamento de Gilberto Freyre e as ideias de nacional propagadas pelo Estado Novo.

77 ORTIZ, Renato. Cultura brasileira e identidade nacional. São Paulo: Brasiliense, 2006. 